\title{
Secondary Parkinsonism in a Patient With a Cerebral Cavernous Hemangioma Treated With Stereotactic Radiosurgery
}

\author{
Seckin Aydin ${ }^{1}$, Aysegul Esen Aydin ${ }^{2}$, Odhan Yuksel $^{3}$, Taner Tanriverdi ${ }^{4}$ \\ 1. Department of Neurosurgery, Prof. Dr. Cemil Tascioglu City Hospital, University of Health Sciences, Istanbul, TUR 2. \\ Department of Neurosurgery, Bakirkoy Research and Training Hospital for Neurology, Neurosurgery and Psychiatry, \\ Istanbul, TUR 3. Department of Neurosurgery, Baskent University School Medicine, Alanya Teaching and Medical \\ Research Center, Alanya, TUR 4. Department of Neurosurgery, Cerrahpasa Medical Faculty, Istanbul University- \\ Cerrahpasa, İstanbul, TUR
}

Corresponding author: Aysegul Esen Aydin, aysegul_esen@hotmail.com

\begin{abstract}
Secondary parkinsonism is defined with some symptoms similar to idiopathic Parkinson's disease, but with different etiologies. And cerebral cavernous hemangioma is one of the rare cases. A 51-year-old, male patient was consulted with tremor, rigidity and bradykinesia on the right upper extremity. The Hoehn and Yahr Parkinson's scale was Stage I. Radiological evaluations showed a deep-seated cerebral cavernous hemangioma at the left posterior insular region. The patient received stereotactic radiosurgery (CyberKnife ${ }^{\circledR}$, Accuray Incorporated, Sunnyvale, CA, USA). Clinical and radiological improvements revealed within follow-up, respectively. Stereotactic radiosurgery may be an alternative treatment for secondary parkinsonism by reducing the risk of re-bleeding and reducing its size.
\end{abstract}

Categories: Radiation Oncology, Neurosurgery

Keywords: cerebral cavernous hemangioma, secondary parkinsonism, stereotactic radiosurgery (cyberknife ${ }^{\circledR}$ )

\section{Introduction}

Parkinsonism is a clinical syndrome characterized by some cardinal findings related to Idiopathic Parkinson's disease including bradykinesia, tremor, rigidity and postural instability [1]. Secondary parkinsonism resembles Idiopathic Parkinson's disease clinically, but etiology is different in secondary parkinsonism including drugs, trauma, normal pressure hydrocephalus, toxins or vascular pathologies [2]. Secondary parkinsonism constitutes approximately $14 \%-16 \%$ of all parkinsonism cases over 40 years of age [3]. The absence of asymmetric symptoms, resting tremor and unresponsiveness to levodopa (L-dopa) treatment at the beginning of the disease differentiates it from Idiopathic Parkinson's disease. In the literature, there have been reported some cases that cerebral cavernous hemangioma ( $\mathrm{CCH}$ ) may be a cause of secondary parkinsonism.

Review began 02/23/2021 Review ended 03/20/2021 Published 03/26/2021

\section{() Copyright 2021}

Aydin et al. This is an open access article distributed under the terms of the Creative Commons Attribution License CC-BY 4.0., which permits unrestricted use, distribution, and reproduction in any medium, provided the original author and source are credited.
In recent years, stereotactic radiosurgery (SRS) is more often performed with wider indications and experience is also increased consequently. It becomes an alternative treatment option for symptomatic deep-seated $\mathrm{CCH}$ that carries high operative risk potentially and also, for patients who refuse surgery [4]. In accordance with this manner, we reported a CCH case treated with SRS located in the left posterior insular region caused secondary parkinsonism. Additionally, we reviewed the limited number of similar cases reported in the literature so far. This study has been conducted in accordance with the Declaration of Helsinki, and an informed consent form was obtained from the patient.

\section{Case Presentation}

A 51-year-old male was admitted to our clinic with a right arm tremor that started six months ago and increased in amplitude one month before the admission. There was no chronic disease in his medical history and laboratory screening showed nothing abnormal. Neurological examination showed parkinsonian tremor with the right hand, bradykinesia, rigidity, mild right upper extremity motor dysfunction and clumsiness. The Hoehn and Yahr Parkinson's scale was Stage I. Magnetic resonance imaging (MRI) revealed $\mathrm{CCH}$ located on the left posterior insular region with 16x15x15 mm in size. Classical hemosiderin rim was noted on T2-weighted image with hypointensity (Figure $1 \mathrm{~A}$ ). Gradient echo image demonstrated the pathognomonic sign (Figure $1 B$ ). L-dopa treatment was started to treat parkinsonian symptoms. However, the patient did not give a response to L-dopa treatment. Firstly, L-dopa dose was increased. Thereafter, multiple medical treatments were initiated because of persistent symptoms and end-of-dose motor fluctuations. Because of the deep-seated location of $\mathrm{CCH}$, surgical evaluation was not performed and the patient underwent SRS CyberKnife ${ }^{\circledR}$ (Accuray Incorporated, Sunnyvale, CA, USA) with 16 Gy dose in a single fraction (Figure $1 \mathrm{C}$ ). The patient continued multiple medical treatments and was followed-up by the neurology department. Radiological evaluations were performed at three-month intervals during the first year and then six-monthly. Symptoms were not worsened in long term follow-up of 54 months, and the 


\section{Cureus}

Hoehn and Yahr Parkinson's scale was still Stage I. Also, a considerable decrease in the size of the CCH developed in follow-up (Figure 1D).

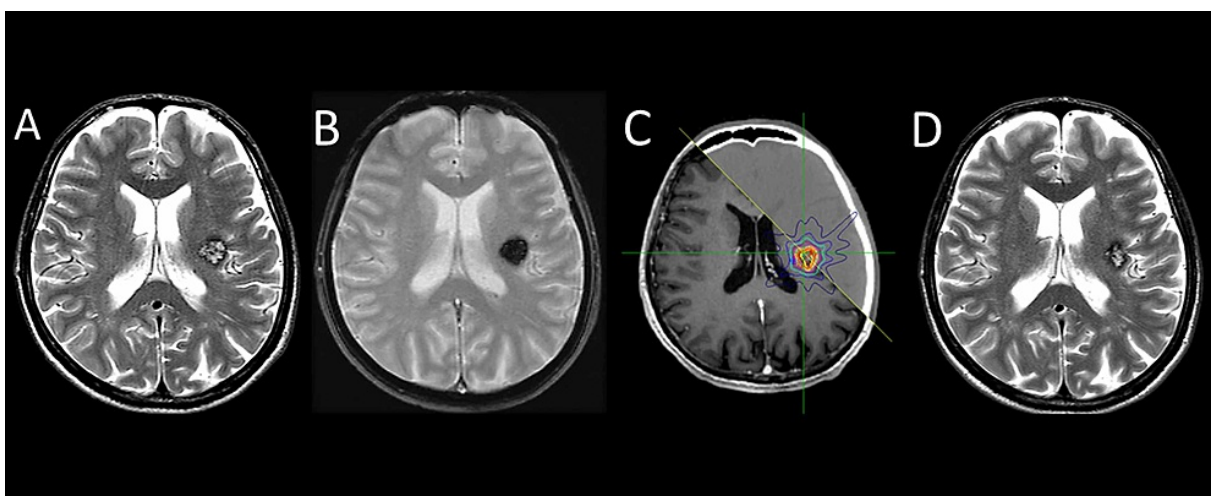

\section{FIGURE 1: Radiological imaging}

MRI axial plane, T2-weighted image shows a cavernous hemangioma with peripheral hemosiderin rim at the left posterior insular region (A), MRI axial plane, gradient echo image shows hemorrhagic lesion (B), a fusion of axial planes of MRI and computed tomography shows the target delineation for cavernous hemangioma with isodose distribution (C), MRI axial plane, T2-weighted image shows a considerable decrease in the size of cavernous hemangioma in $\mathbf{3 0}$ months follow-up after CyberKnife (D).

\section{Discussion}

$\mathrm{CCH}$ is a vascular lesion with irregular thin walls without intervening cerebral tissue and capillary. Sinusoidal and cavernous types have been reported so far [5]. Terminologically, it is also described as cavernoma, cavernous angioma, venous vascular malformation or vascular hamartoma.

The prevalence of $\mathrm{CCH}$ is $0.5 \%$ and it constitutes $5 \%-13 \%$ of all cerebrovascular malformations. Seizure and bleeding constitute the most common neurological symptoms. The natural history of $\mathrm{CCH}$ reveals a "temporal clustering" pattern describing long bleeding-free intervals in between symptomatic episodes. The emerging clinical symptoms due to bleeding usually tend to be improved by the resorption of the blood, unless there is a permanent injury in the healthy tissues. They are mostly located in the supratentorial areas. Deep-seated CCHs are not common, and the location at the basal ganglia has been reported to be only $6 \%$ $8 \%[5,6]$. Developing secondary parkinsonism is exceptional during the clinical course of this pathology. The annual bleeding rate is around $0.1 \%-2.5 \%$ per lesion and $0.25 \%-16.5 \%$ per patient [7]. The history of prior bleedings increases the risk and, when the bleeding is confirmed twice by both clinical and radiological findings, then, the risk is reported to be at least $34 \%$ per year [8].

MRI is the gold standard for the diagnosis of $\mathrm{CCH}$. The lesion is usually characterized by a central hypointensity in a reticular form on T2-weighted images and a peripheral hypointense ring due to the collection of hemosiderin. Gradient echo images are highly sensitive and make the diagnosis easier. Zabramski et al. classified CCH's into four groups based on their radiographic features [9]. Our case belongs to type 2 depending on this classification.

The efficiency of SRS has long been known for the treatment of central nervous system primary tumors and metastases [10]. SRS can also be utilized to treat movement disorders [11]. The effect mechanism is to constitute focal lesions with thalamotomy or pallidotomy. Successful treatment results were obtained in patients who are not suitable for open surgery. In the literature, there are studies reporting that intractable tremor improved over $90 \%$ in patients who underwent thalamotomy with SRS [12]. SRS has also been performed for vascular brain pathologies for a long time. It is known that SRS causes progressive endothelial cell proliferation and luminal closure on arteriovenous malformation [13]. Some authors claimed that SRS treats CCHs by a similar mechanism $[14,15]$.

Treatment of CCH is still controversial. Due to a lower risk of bleeding, incidentally diagnosed CCHs are treated with conservative modalities. On the other hand, symptomatic and easily accessible CCHs can be operated with microsurgery. If deep-seated lesions reach the pial surface and the bleeding results in progressive neurological deterioration, surgical intervention will be required [16]. A similar approach is also considered to be appropriate for cases with intractable epilepsy [17]. It has been argued that SRS may be a good alternative in selected patients with deep-localized CCH, who are considered to be at high risk of surgery [6]. When SRS was performed in these patients, the risk of re-bleeding was demonstrated to be decreased significantly [18]. Also, it has been reported that CCH patients treated with SRS have a regression of the size in follow-up periods longer than two years [6]. 
On the other hand, where CCHs are treated conservatively within long follow-up periods, decreasing the size may occur due to the nature of the CCH [19]. It is not clear whether SRS or the nature of the CCH is effective in ameliorating the patient's symptoms. In our case, no clinical or radiological findings to consider re-

bleeding were identified during a follow-up period of 54 months. Furthermore, regression in the lesion was observed in the most recent MRI examination.

\section{Conclusions}

We consider that the $\mathrm{CCH}$ in the cortico-striato-thalamic pathway might potentially have exerted pressure or caused bleeding leading to the parkinsonism symptoms of the patient. SRS has started to gain importance in the treatment of many neurovascular and neuro-oncological brain pathologies with an expanding application field. In this report, we would like to highlight for the first time that SRS might be an alternative treatment of this rare entity.

\section{Additional Information \\ Disclosures}

Human subjects: Consent was obtained or waived by all participants in this study. Conflicts of interest: In compliance with the ICMJE uniform disclosure form, all authors declare the following: Payment/services info: All authors have declared that no financial support was received from any organization for the submitted work. Financial relationships: All authors have declared that they have no financial relationships at present or within the previous three years with any organizations that might have an interest in the submitted work. Other relationships: All authors have declared that there are no other relationships or activities that could appear to have influenced the submitted work.

\section{Acknowledgements}

Preparation for publication of this article is partly supported by Turkish Neurosurgical Society.

\section{References}

1. Hayes MT: Parkinson's disease and parkinsonism. Am J Med. 2019, 132:802-807. 10.1016/j.amjmed.2019.03.001

2. Ng DC: Parkinson's disease: diagnosis and treatment. West J Med. 1996, 165:234-240.

3. Lang AE, Lozano AM: Parkinson's disease. First of two parts. N Engl J Med. 1998, 339:1044-1053. 10.1056/NEJM199810083391506

4. Dalyai RT, Ghobrial G, Awad I, et al.: Management of incidental cavernous malformations: a review . Neurosurg Focus. 2011, 31:E5. 10.3171/2011.9.FOCUS11211

5. Gross BA, Lin N, Du R, Day AL: The natural history of intracranial cavernous malformations . Neurosurg Focus. 2011, 30:E24. 10.3171/2011.3.FOCUS1165

6. Nagy G, Razak A, Rowe JG, et al.: Stereotactic radiosurgery for deep-seated cavernous malformations: a move toward more active, early intervention. Clinical article. J Neurosurg. 2010, 113:691-699. 10.3171/2010.3.JNS091156

7. Lunsford LD, Khan AA, Niranjan A, Kano H, Flickinger JC, Kondziolka D: Stereotactic radiosurgery for symptomatic solitary cerebral cavernous malformations considered high risk for resection. J Neurosurg. 2010, 113:23-29. 10.3171/2010.1.JNS081626

8. Karlsson B, Kihlström L, Lindquist C, Ericson K, Steiner L: Radiosurgery for cavernous malformations. J Neurosurg. 1998, 88:293-297. 10.3171/jns.1998.88.2.0293

9. Zabramski JM, Wascher TM, Spetzler RF, et al.: The natural history of familial cavernous malformations: results of an ongoing study. J Neurosurg. 1994, 80:422-432. 10.3171/jns.1994.80.3.0422

10. Suh JH: Stereotactic radiosurgery for the management of brain metastases . N Engl J Med. 2010, 362:11191127. 10.1056/NEJMct0806951

11. Niranjan A, Raju SS, Kooshkabadi A, Monaco E 3rd, Flickinger JC, Lunsford LD: Stereotactic radiosurgery for essential tremor: retrospective analysis of a 19-year experience. Mov Disord. 2017, 32:769-777. 10.1002/mds. 26925

12. Frighetto L, Bizzi J, Annes RD, Silva Rdos S, Oppitz P: Stereotactic radiosurgery for movement disorders . Surg Neurol Int. 2012, 3:S10-6. 10.4103/2152-7806.91605

13. Szeifert GT, Timperley WR, Forster DMC, Kemeny AA: Histopathological changes in cerebral arteriovenous malformations following Gamma Knife radiosurgery. Prog Neurol Surg. 2007, 20:212-219. 10.1159/000100119

14. Monaco EA, Khan AA, Niranjan A, et al.: Stereotactic radiosurgery for the treatment of symptomatic brainstem cavernous malformations. Neurosurg Focus. 2010, 29:E11. 10.3171/2010.7.FOCUS10151

15. Nyáry I, Major O, Hanzély Z, Szeifert GT: Histopathological findings in a surgically resected thalamic cavernous hemangioma 1 year after 40-Gy irradiation. J Neurosurg. 2005, 102:56-58. 10.3171/jns.2005.102.s_supplement.0056

16. Mathiesen T, Edner G, Kihlström L: Deep and brainstem cavernomas: a consecutive 8-year series . J Neurosurg. 2003, 99:31-37. 10.3171/jns.2003.99.1.0031

17. Cossu M, Raneri F, Casaceli G, Gozzo F, Pelliccia V, Lo Russo G: Surgical treatment of cavernoma-related epilepsy. J Neurosurg Sci. 2015, 59:237-253.

18. Lu XY, Sun H, Xu JG, Li QY: Stereotactic radiosurgery of brainstem cavernous malformations: a systematic review and meta-analysis. J Neurosurg. 2014, 120:982-987. 10.3171/2013.12.JNS13990

19. Clatterbuck RE, Moriarity JL, Elmaci I, Lee RR, Breiter SN, Rigamonti D: Dynamic nature of cavernous 


\section{Cureus}

malformations: a prospective magnetic resonance imaging study with volumetric analysis. J Neurosurg. 2000, 93:981-986. 10.3171/jns.2000.93.6.0981 